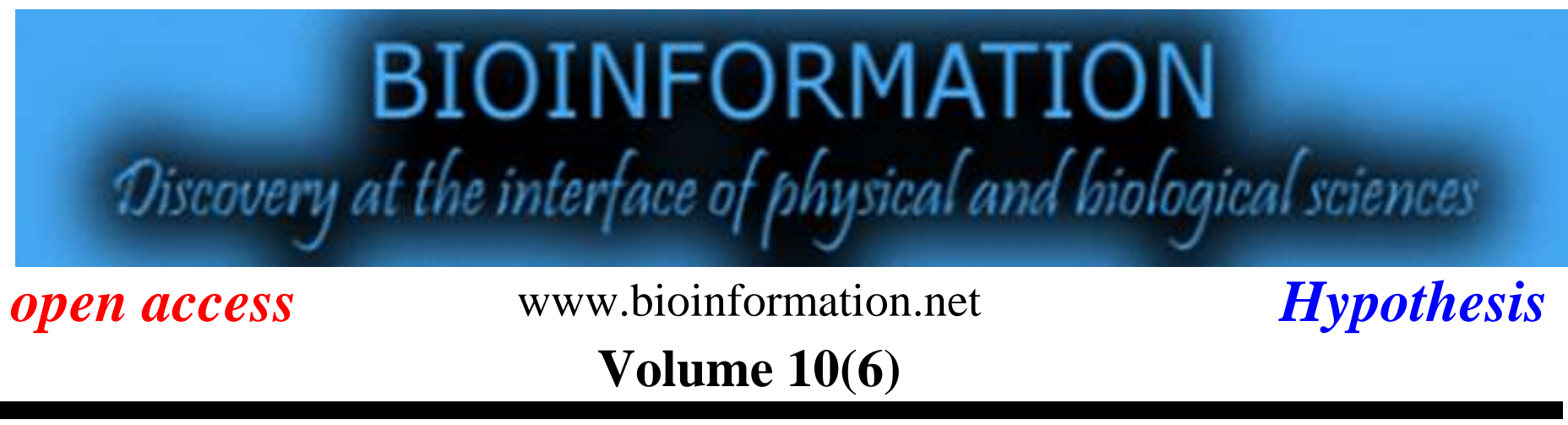

\title{
A study on risk factors for Parkinson's disease in Indian population
}

\author{
Vineeta Gupta1, Ravindra Kumar Garg², Kamlesh Kumar Pant ${ }^{1}$ \& Sanjay Khattri ${ }^{*}$ \\ 1Department of Pharmacology \& Therapeutics, King George's Medical University, Lucknow-226003, Uttar Pradesh, India; \\ 2Department of Neurology, King George's Medical University, Lucknow-226003, Uttar Pradesh, India; Sanjay Khattri - Email: \\ pharmacsmmu01@gmail.com; Phone: +91 5222257448 (O); *Corresponding author
}

Received June 07, 2014; Accepted June 07, 2014; Published June 30, 2014

\begin{abstract}
:
Parkinson's disease is the second most common neurodegenerative disorder. The exact cause of selective dopaminergic neurodegeneration is unknown, but it is supposed that etiology of Parkinson's disease is multifactorial and consists of an interaction between environmental factors and genetic predisposition. To find out the association between environmental factors and risk of Parkinson's disease, a case control study was designed including 97 Parkinson's disease patients and 97 controls. Logistic regression analysis was used to determine the risk factors for Parkinson's disease. Results from the present study showed that gender, religion, education, place of living, occupation, dietary habits, tobacco chewing, smoking, alcohol intake, and head injury had no association with PD. However, chemical exposure and well water drinking were significantly associated with PD, which concluded that environmental factors could act as a risk factor for PD in some way.
\end{abstract}

Key Words: Parkinson's disease, risk factors, chemical exposure, well water

\section{Background:}

Parkinson's disease (PD) is the second most common neurodegenerative disorder after Alzheimer's disease [1], which affects $\sim 1-2 \%$ of the population above age 65 and $4-5 \%$ above age 85 [2] with a higher prevalence in men [3]. The origin of the selective dopaminergic neuronal degeneration in PD is unknown, but it may involve oxidative stress, mitochondrial dysfunction, apoptotic mechanisms, and accumulation of altered proteins [4]. It is also supposed that environmental factors may contribute to PD. The etiology of most neurodegenerative disorders is multifactorial and consists of an interaction between environmental factors and genetic predisposition [5]. Discovery of 1-methyl-4-phenyl-1,2,3,6tetrahydropyridine (MPTP)-induced parkinsonism generated interest in the search for environmental risk factors in the pathogenesis of PD [6]. The role of pesticide exposure in PD has long been suspected, but the specific causative agents and the underlying mechanisms are not fully understood. There are evidences, which link PD etiology with long-term/low-dose exposure to pesticides such as paraquat, maneb, dieldrin, pyrethroids, and organophosphates. Most of these pesticides share common features, namely the ability to induce oxidative stress, mitochondrial dysfunction, alpha-synuclein fibrillization, and neuronal cell loss [5].

Certain types of professions such as farming, carpentry, cleaning, and welding, cigarette smoking, the use of coffee/caffeine, non-steroidal anti-inflammatory drugs, and head trauma might have some type of association with PD [7]. Beside this, the influence of well-water drinking [8], rural living [9], and nutritional factors [10] have also been reported with the risk of PD. In this context, the present study was designed to find out the association between environmental factors and risk of PD.

\section{Methodology:}

Participants

The present study included 97 patients with Parkinson's disease and equal number of controls. PD patients of age between $\geq 40-\leq 80$ years were recruited from the outpatient door 
of Neurology, King George's Medical University, Lucknow, Uttar Pradesh, India, from May 2010 to January 2013. Diagnosis was made according to the UK Parkinson 's Disease Society Brain Bank criteria [11]. Patients with secondary parkinsonism or parkinson-plus diseases such as multiple system atrophy, progressive supranuclear palsy, corticobasal degeneration, and dementia with Lewy bodies were excluded from the study. Neurologically healthy controls were recruited from the local community. The absence of disease was confirmed by clinical history and physical examination. The controls were neither related to one another, nor to PD patients. Controls having a history of any neurological disorder were excluded from the study. The purpose of the study was explained to all of them. Written informed consent for the participation in the study was obtained prior to enrollment from all the participants. This study was approved by the institutional ethics committee.

\section{Data collection}

A detailed structured proforma was used to record the information. All the participants underwent same questionnaire. Patient's data was collected during the visit to the outpatient door of Neurology, King George's Medical University, Lucknow, Uttar Pradesh, India. Information from the participants was obtained regarding: a) demographic data: age, age at PD onset, weight, gender, religion, education, place of living and occupation; b) environmental factors: chemical exposure, dietary habits, source of drinking water, tobacco chewing, smoking, and alcohol intake; c) history of other diseases: hypertension, diabetes and tuberculosis; and d) history of head injury. On the basis of education, participants were divided into illiterate, up to high school, up to intermediate, and more than graduation. Place of living was divided into rural and urban areas. Occupations of the participants were classified into service class, professionals, farmers, business persons, housewives, labors, and unemployed. Chemical exposure includes exposure to insecticides, herbicides, rodenticides, and other toxic chemical such as laboratory chemicals, heavy metals, farming chemicals, fertilizers etc. Dietary habits were grouped into two categoriesvegetarian and non-vegetarian. The participant was considered non-vegetarian if he consumes food such as egg, fish, meat etc. Source of drinking water was divided into three groups- well water, hand pump and tap water. Adverse habits include tobacco chewing, smoking (cigarette / bidi) and alcohol intake. Data were also recorded for other common diseases and head injury.

\section{Statistical analysis}

All the analysis was carried out using SPSS 16.0 version (Chicago, Inc. USA). The results are presented in mean \pm SD and percentages. The dichotomous variable was compared by using Chi-square test. Risk factors showing significance in univariate analysis were subjected to multivariate analysis. The logistic regression analysis was carried out to evaluate the risk factors for PD. The odds ratio (OR) and its $95 \%$ confidence interval (CI) were calculated. The $p$-value $<0.05$ was considered significant.

\section{Results:}

More than half of the PD patients $(71.1 \%)$ and controls $(70.1 \%)$ were males with mean age of $56.34 \pm 9.58$ and $53.30 \pm 833$ years, respectively $(p>0.05)$. The average onset age of $P D$ patients was $52.59 \pm 11.18$ years with duration of disease $37.64 \pm 32.93$ months.
The average weight of PD patients and controls was $53.98 \pm 10.70$ and $56.40 \pm 7.45 \mathrm{~kg}$, respectively ( $p>0.05)$. Nonsignificant differences in age and weight between PD patients and controls indicated the comparability of both the groups. Results are shown in Table 1 \& Table 2 (see supplementary material). Gender, religion, education, place of living, occupation, dietary habits, tobacco chewing, smoking, alcohol intake, head injury, and other diseases such as hypertension, tuberculosis and diabetes were not associated with PD. However, people who were consuming well water (OR: 4.45; 95\% CI: 1.96-10.10) and who were exposed to any type of chemical exposure (OR: 6.57; 95\% CI: 2.86-15.09) were at increased risk of developing PD.

\section{Discussion:}

The findings of the present study were hospital based not from the community-based epidemiological surveys. According to the results, gender was not found to be as a risk factor. However, Behari et al found gender as a risk factor [6], which was contrary to our finding. Most of the studies are dominant with male proportion, especially in the Indian context. Thus, hospital based studies may be misleading. In the present study, male to female ratio was 2.46:1 in PD group and 2.34:1 was among controls. The present study showed that place of residence involving rural living was not a significant risk factor, whereas any type of chemical exposure was found to be significantly associated with PD. Most of the studies showed that an increased risk of pesticide exposure was associated with an increased risk of PD with rural living. However, association of rural living with PD is controversial. Some studies favor the hypothesis for the interrelation between PD and rural living [9, $12,14]$ but some reports showed no association between them $[6,13,15]$; for example, the findings of the present study. The possible reason behind it might be recruitment of PD patients and controls from the same area. Occupational status has also been investigated for PD and controls, but it was not associated with PD in agreement with several studies [15-17]. However, Tanner et al found that some professions were associated with postural instability and gait difficulty subtype of Parkinsonism [18]. Occupation involving farming is very common among rural people. However, in the present study farming was not significantly associated with PD, but they showed 1.43 folds increased chances for developing PD. Some studies favor farming as a risk factor of PD $[9,13]$, whereas other studies do not $[6,8,16,17,19,20]$. Education and religion were also not associated with the risk of PD in this study. Observations for education were also consistent with earlier studies [15, 16].

It is well known that farming is linked to chemical exposure. A significant association was found between PD and chemical exposure in the present study. This observation was similar to the findings of others $[\mathbf{1 3}, \mathbf{1 8}, \mathbf{2 1}, \mathbf{2 2}]$. However, some casecontrol studies found no clear association $[8,14,17]$ and one study also reported no association between them [23]. Pesticides and other chemical agents have attracted the attention of investigators as a PD risk factor, because MPTP may cause many cases of secondary parkinsonism and is structurally similar to paraquet [24]. It can be assumed that family members of farmers and also people of other professions such as shopkeepers and small businessman who handle pesticides during cultivation of land seasonally with longer years of exposure to pesticides might develop PD in their 
lifetime, which indicated that direct exposure to pesticides was probably more important than rural living or farming as a risk factor [6]. However, in contrast, Jimenez et al reported that past exposure to pesticides does not appear to be associated with an increased risk of developing PD [25]. Well water consumption has also been found associated with increased risk of developing PD $[6,8,9,14]$ as well as in the present study, although in other reports such association was not found [13, 23]. Consumption of well water for more than 10 years duration result in a two-fold increase in the occurrence of PD [6]. Jimenez et al also reported that only prolonged exposures of 30 years or longer were significantly different between PD patients and controls [25], whereas consumption of well water for less than 10 years did not show any significant difference. Well water could probably act as a carrier of a potentially toxic agent or an infective agent. However, no difference was found in chemical analysis between well water consumed by PD patients and controls. This could suggest that chronic exposure to exogenous toxic agents may be responsible in some way [6].

Dietary pattern might involve with the occurrence of PD, because an increased risk of PD development after exposure to nuts and seeds has been reported; the protective effect of peanuts on females and salads with dressing on males is also observed. Salads eaten by most Indians are generally raw vegetables tossed with salt, pepper and lime juice. Salad dressings and salad oils are only used by a very few people and could not have been a major risk or protective factor in the Indian context. Similarly, peanuts are consumed universally by people of all strata and again were not likely to be a major risk or protective factor [6]. In our study, vegetarian and nonvegetarian dietary habits did not show any significant association with PD. This result was consistent with previous studies [6,12], whereas Fall et al suggested that nutritional factors could be of etiologic importance in PD [10]. A reduced risk for PD among cigarette smokers has been observed in several studies $[9, \mathbf{1 2}, 23,26,27]$. Behari et al observed the protective effect of cigarette smoking in smokers of 20 years duration only. People who smoked for more than 20 years did not enjoy this protective effect. It might be possible that those who smoked for more than 20 years had increased mortality from other smoking-related diseases [6]. Morano et al found that cigarette smoking habit in males was near to statistical significance [14]. Cigarette smoking may exert its protective effect through various means: (a) It contains monoamine oxidase-B (MAO-B) inhibitor activity, MAO-B breaks down dopamine, releasing free radicals, which, in turn damage nigral cells (b) Nicotine up regulates nicotinic receptors masking early symptoms of PD (c) Carbon monoxide from smoke reduces free radicals [12]. However, we found no significant association of smoking with PD, which was similar to earlier studies [28, 29], although inverse association of tobacco and tobacco smoking with PD were found in other studies $[19,26,30]$. Alcohol intake did not carry any significant association with the occurrence of PD as observed in previous studies $[6,12,15,27,31]$ as well as in the present study. A decreased risk of developing PD with alcohol intake habit in males is also reported [14].

Some previous studies reported that head injury might increase the risk of PD $[32,33]$, but this observation was not found in the present study, in agreement with the findings of the others [12, 29]. Goldman et al suggested that head injury alone was not associated with PD risk. It may initiate and/or accelerate neurodegeneration when levels of synuclein are high [34]. The results from the present study showed that PD was not associated with hypertension, tuberculosis and diabetes. However, these results are preliminary; more studies are warranted to prove chemical exposure and well water drinking as a significant risk factors for PD.

\section{Conclusion:}

Results from the present study showed that gender, religion, education, place of living, occupation, dietary habits, tobacco chewing, smoking, alcohol intake, and head injury had no association with PD. However, chemical exposure and well water drinking were significantly associated with PD, which concluded that environmental factors could act as a risk factor for PD in some way.

\section{Acknowledgement:}

The authors are thankful to all the participants who participated in this study.

\section{Conflict of Interest}

The authors report that they have no conflict of interest.

\section{References:}

[1] Tanner CM \& Goldman SM, Neurol Clin. 1996 14: 317 [PMID: 8827174]

[2] Bisaglia M et al. FASEB J. 2009 23: 329 [PMID: 18948383]

[3] Dluzen DE \& McDermott JL, J Gend Specif Med. 2000 3: 36 [PMID: 11253381]

[4] Reale $M$ et al. Brain Behav Immun. 2009 23: 55 [PMID: 18678243]

[5] Baltazar MT et al. Toxicol Lett. 2014 [Epub ahead of print] [PMID: 24503016]

[6] Behari Met al. J Neurol Sci. 2001 190: 49 [PMID: 11574106]

[7] Chade AR et al. J Neural Transm Suppl. 2006 70: 147 [PMID: 17017522]

[8] Wright JM \& Keller-Byrne, J Arch Environ Occup Health. 2005 60: 32 [PMID: 16961006]

[9] Zorzon M et al. Acta Neurol Scand. 2002 105: 77 [PMID: 11903115]

[10] Fall PA et al. Mov Disord. 1999 14: 28 [PMID: 9918341]

[11] Hughes AJ et al. J Neurol Neurosurg Psychiatry. 1992 55: 181 [PMID: 1564476]

[12] Sanyal J et al. Can J Neurol Sci. 2010 37: 637 [PMID: 21059511]

[13] Gorell JM et al. Neurology. 1998 50: 1346 [PMID: 9595985]

[14] Morano A et al. Acta Neurol Scand. 1994 89: 164 [PMID: 8030397]

[15] Kuopio AM et al. Mov Disord. 1999 14: 928 [PMID: 10584666]

[16] Rocca WA et al. Mov Disord. 1996 11: 201 [PMID: 8684392]

[17] Firestone JA et al. Am J Ind Med. 2010 53: 217 [PMID: 20025075]

[18] Tanner CM et al. Arch Neurol. 2009 66: 1106 [PMID: 19752299]

[19] Kyrozis A et al. Eur J Epidemiol. 2013 28: 67 [PMID: 23377703]

[20] Tanaka K et al. BMC Neurol. 2011 11: 83 [PMID: 21733194]

[21] Vanacore N et al. Neurol Sci. 2002 Suppl 2: S119 [PMID: 12548372] 
[22] Baldi I et al. Neuroepidemiology. 2003 22: 305 [PMID: 12902626]

[23] Taylor CA et al. Am J Med Genet. 1999 88: 742 [PMID: 10581500]

[24] Berry C et al. Cell Death Differ. 2010 17: 1115 [PMID: 20094060]

[25] Jiménez-Jiménez FJ et al. Mov Disord. 1992 7: 149 [PMID: 1584237]

[26] Ritz B et al. Arch Neurol. 2007 64: 990 [PMID: 17620489]

[27] Checkoway H et al. Am J Epidemiol. 2002 155: 732 [PMID: 11943691]
[28] Wang WZ et al. Neuroepidemiology. 1993 12: 209 [PMID: 8272180]

[29] McCann SJ et al. Neuroepidemiology. 1998 17: 310 [PMID: 9778597]

[30] Zanetti R et al. Melanoma Res. 2006 16: 201 [PMID: 16718266]

[31] Liou HH et al. Neurology. 1997 48: 1583 [ PMID: 9191770]

[32] Lee PC et al. Neurology. 2012 79: 2061 [PMID: 23150532]

[33] Goldman SM et al. Ann Neurol. 2006 60: 65 [PMID: 16718702]

[34] Goldman SM et al. Ann Neurol. 2012 71: 40 [PMID: 22275250]

Edited by $P$ Kangueane Citation: Gupta et al. Bioinformation 10(6): 342-346 (2014) License statement: This is an open-access article, which permits unrestricted use, distribution, and reproduction in any medium, for non-commercial purposes, provided the original author and source are credited 


\section{Supplementary material:}

Table 1: Association of risk factors with PD

\begin{tabular}{|c|c|c|c|c|c|}
\hline Risk Factors & & $\begin{array}{l}\text { PD } \\
(n=97)\end{array}$ & $\begin{array}{l}\text { Controls } \\
(n=97)\end{array}$ & Chi-square & p-value \\
\hline \multirow[t]{2}{*}{ Gender } & Male & $69(71.1 \%)$ & $68(70.1 \%)$ & 0.02 & 0.87 \\
\hline & Female & $28(28.9 \%)$ & $29(29.9 \%)$ & & \\
\hline \multirow[t]{2}{*}{ Religion } & Hindu & $77(79.4 \%)$ & $79(81.4 \%)$ & 0.13 & 0.71 \\
\hline & Muslim & $20(20.6 \%)$ & $18(18.6 \%)$ & & \\
\hline \multirow[t]{4}{*}{ Education } & Illiterate & $48(49.5 \%)$ & $46(47.4 \%)$ & 0.21 & 0.97 \\
\hline & Up to high school & $16(16.5 \%)$ & $17(17.5 \%)$ & & \\
\hline & Up to Intermediate & $19(19.6 \%)$ & $21(21.6 \%)$ & & \\
\hline & Graduate + & $14(14.4 \%)$ & $13(13.4 \%)$ & & \\
\hline \multirow[t]{2}{*}{ Place of living } & Rural & $39(40.2 \%)$ & $28(28.9 \%)$ & 2.75 & 0.10 \\
\hline & Urban & $58(59.8 \%)$ & $69(71.1 \%)$ & & \\
\hline \multirow[t]{7}{*}{ Occupation } & Service class & $13(13.4 \%)$ & $20(20.6 \%)$ & 8.54 & 0.20 \\
\hline & Professionals & $4(4.1 \%)$ & $6(6.2 \%)$ & & \\
\hline & Farmers & $24(24.7 \%)$ & $12(12.4 \%)$ & & \\
\hline & Business persons & $7(7.2 \%)$ & $5(6.2 \%)$ & & \\
\hline & Housewives & $26(26.8 \%)$ & $29(29.9 \%)$ & & \\
\hline & Labors & $9(9.3 \%)$ & $15(15.5 \%)$ & & \\
\hline & Unemployed & $14(14.4 \%)$ & $10(9.3 \%)$ & & \\
\hline \multirow[t]{2}{*}{ Chemical exposure } & Yes & $36(37.1 \%)$ & $8(8.2 \%)$ & 23.04 & $0.0001^{*}$ \\
\hline & No & $61(62.9 \%)$ & $89(91.8 \%)$ & & \\
\hline \multirow[t]{2}{*}{ Dietary habit } & Vegetarian & $40(41.2 \%)$ & $43(44.3 \%)$ & 0.19 & 0.66 \\
\hline & Non-vegetarian & $57(58.8 \%)$ & $54(55.7 \%)$ & & \\
\hline \multirow{2}{*}{$\begin{array}{l}\text { Source of } \\
\text { drinking }\end{array}$} & Well & $29(29.9 \%)$ & $11(11.3 \%)$ & 13.96 & $0.001^{*}$ \\
\hline & Hand Pump & $36(37.1 \%)$ & $32(33.0 \%)$ & & \\
\hline water & Tap & $32(33.0 \%)$ & $54(55.7 \%)$ & & \\
\hline \multirow[t]{2}{*}{ Tobacco } & Yes & $31(32.0 \%)$ & $39(40.2 \%)$ & 1.43 & 0.23 \\
\hline & No & $66(68.0 \%)$ & $58(59.8 \%)$ & & \\
\hline \multirow[t]{2}{*}{ Smoking } & Yes & $43(44.3 \%)$ & $38(39.2 \%)$ & 0.53 & 0.46 \\
\hline & No & $54(55.7 \%)$ & $59(60.8 \%)$ & & \\
\hline \multirow[t]{2}{*}{ Alcohol } & Yes & $18(18.6 \%)$ & $27(27.8 \%)$ & 2.34 & 0.12 \\
\hline & No & $79(81.4 \%)$ & $70(72.2 \%)$ & & \\
\hline \multirow[t]{2}{*}{ Head injury } & Yes & $3(3.1 \%)$ & $1(1.0 \%)$ & 1.02 & 0.31 \\
\hline & No & $94(96.9 \%)$ & $96(99.0 \%)$ & & \\
\hline \multirow[t]{2}{*}{ Hypertension } & Yes & $12(12.4 \%)$ & $14(14.4 \%)$ & 0.18 & 0.67 \\
\hline & No & $85(87.6 \%)$ & $83(85.6 \%)$ & & \\
\hline \multirow[t]{2}{*}{ Tuberculosis } & Yes & $2(2.1 \%)$ & $4(4.1 \%)$ & 0.69 & 0.41 \\
\hline & No & $95(97.9 \%)$ & $93(95.9 \%)$ & & \\
\hline \multirow[t]{2}{*}{ Diabetes } & Yes & $4(4.1 \%)$ & $10(10.3 \%)$ & 2.77 & 0.09 \\
\hline & No & $93(95.9 \%)$ & $87(89.7 \%)$ & & \\
\hline
\end{tabular}

$\mathrm{PD}=$ Parkinson's disease

* Significant $(\mathrm{p}<0.05)$

Table 2: Significant risk factors for PD using logistic regression analysis

\begin{tabular}{|c|c|c|c|c|c|c|}
\hline Risk Factors & Beta coefficient & SE & OR & $\begin{array}{l}95 \% \mathrm{CI} \\
\text { Lower }\end{array}$ & Upper & p-value \\
\hline \multicolumn{7}{|c|}{ Source of drinking water } \\
\hline Well & 1.49 & 0.42 & 4.45 & 1.96 & 10.10 & 0.0001 \\
\hline Hand Pump & 0.64 & 0.33 & 1.90 & 1.00 & 3.62 & 0.052 \\
\hline Tap & & & Ref. & & & \\
\hline \multicolumn{7}{|c|}{ Chemical exposure } \\
\hline Yes & 1.88 & 0.43 & 6.57 & 2.86 & 15.09 & 0.0001 \\
\hline No & & & Ref. & & & \\
\hline
\end{tabular}

$\mathrm{SE}=$ Standard error; $\mathrm{OR}=$ Odds ratio; $\mathrm{CI}=$ Confidence interval 